BACKGROUND and aims: Although the participation of cytokines in the pathogenesis of rheumatoid arthritis (RA) seems to be unequivocal, their relationship with current serum markers of this disease is not clear. The present study analyses whether there is any correlation between the levels of tumour necrosis factor- $\alpha$ (TNF- $\alpha$ ), interlukin-2 soluble receptor (sIL-2R) and the concentrations of C-reactive protein (CRP), erythrocyte sedimentation rate (ESR) and $\beta 2^{-m i c r o g l o b u l i n}$ in a group of 21 patients with RA, all rheumatoid factor positive.

Metbods : The levels of TNF- $\alpha$ and SIL-2R were analysed in association with other parameters of inflammation (ESR, CRP and $\beta^{2-m i c r o g l o b u l i n) . ~}$

Results : In comparison with the control group, RA patients presented high median levels of both cytokines, TNF- $\alpha(6.4 \mathrm{pg} / \mathrm{ml})$ and sIL-2R $(56 \mathrm{pmol} / \mathrm{L})$, as well as of ESR $(34 \mathrm{~mm} / \mathrm{h})$, CRP $(0.9 \mathrm{mg} / \mathrm{dl})$ and

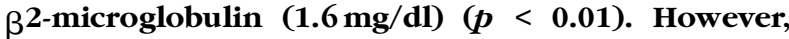
only ESR levels in the RA group significantly differ from the control group $(p<0.01)$. No correlation was found between the inflammatory parameters.

Conclusions : These results suggested that TNF- $\alpha$ and slL-2R levels are up-regulated in RA patients but did not significantly differ from the control group. Due to the chronic course of this disease, other inflammatory markers must be identified in order to provide early therapeutic strategies to these patients.

Key words: Rheumatoid arthritis, Erythrocyte sedimentation rate, C-reactive protein, $\beta_{2}$-Microglobulin, Cytokines

\section{Tumour necrosis factor- $\alpha$, interleukin-2 soluble receptor and different inflammatory parameters in patients with rheumatoid arthritis}

\author{
Tânia Silvia Fröde ${ }^{1, C A}$, Patrícia Tenconi², \\ Marilei Reynaud Debiasi ${ }^{2}$ and \\ Yara Santos Medeiros ${ }^{3}$
}

${ }^{1}$ Department of Clinical Analysis, Center of Healthy Sciences, ${ }^{2}$ Laboratório Médico Santa Luzia and ${ }^{3}$ Department of Pharmacology, Center of Biological Sciences, Universidade Federal de Santa Catarina, Campus Universitário - Trindade, 88040-970

Florianópolis, SC, Brazil

${ }^{\mathrm{CA}}$ Corresponding Author
Fax: $+5548244-0936$
E-mail: taniafrode@zipmail.com.br

\section{Introduction}

Rheumatoid arthritis (RA) is a systemic autoimmune disorder of unknown aetiology ${ }^{1}$ whose major distinctive feature is a chronic, symmetric, and erosive synovitis of peripheral joints. Its aetiology is unknown, and definitive diagnosis depends predominantly on characteristic clinical features, typical radiographic findings, the presence of rheumatoid factor (RF), and elevated erithrocyte sedimentation rate (ESR)/C-reactive protein (CRP). ${ }^{2,3}$ Failure to meet these criteria does not therefore exclude the diagnosis, especially during the early stages of the disease. Hence, diagnosis is often established months or even years after the first appearance of symptoms, at a stage where cartilage destruction has already propagated to an irreversible state. ${ }^{4,5}$

Although the initiating event in RA has not yet been defined, a growing body of evidence indicates that cytokines may help the development and the perpetuation of the chronic inflammatory state. Among the cytokines involved in RA, tumour necro- sis factor- $\alpha\left(\mathrm{TNF}_{-} \alpha\right)$ is believed to be dominant. ${ }^{6,7}$ This cytokine is present in both the synovial cavity and the blood of RA patients. ${ }^{7}$ In relation to interleukin (IL)-2, this cytokine is generally considered to elicit pro-inflammatory effects that exacerbate $T$ helper cell type 1-mediated disease states, such as autoimmune arthritis. It has also been demonstrated that IL-2 mRNA is markedly increased during the acute stage of collagen-induced arthritis, an animal model of rheumatoid arthritis. ${ }^{8}$ In this condition, IL2 protein and the IL-2 soluble receptor (sIL-2R) are preferentially expressed at disease onset, in comparison with later stages of the disease. ${ }^{9}$ However, the studies that have addressed this theme have shown discordant results since they have reported evidence pro and against an association between the current proposed markers of this disease (CRP and ESR) and cytokines (TNF- $\alpha$ and sIL-2R). In the present study, we examined this issue again by evaluating whether there is any correlation between cytokine (TNF- $\alpha$ and sIL-2R) levels and inflammatory parameters such as ESR, CRP, and $\beta_{2}$-microglobulin concentrations. 
Table 1. Clinical and laboratorial features of the studied groups

\begin{tabular}{lcc}
\hline Parameter & RA & Control \\
\hline Sex (female:male) & $18: 3$ & $7: 0$ \\
Age (years) & $36(16-75)^{*}$ & $29(20-75)$ \\
Haemoglobin $(\mathrm{g} / \mathrm{dl})$ & $13.6(10.1-15.1)$ & $13.2(11.7-14.5)$ \\
Haematocrit $\%)$ & $40.4(29.7-46.3)$ & $39.5(36.7-45.1)$ \\
Platelet number $\left(\times 10^{3} \mathrm{~mm}^{3}\right)$ & $237(148-795)$ & $290(205-344)$ \\
Granulocytes $\left(\times 10^{3} \mathrm{~mm}^{3}\right)$ & $4.7(2.79-16.7)$ & $4.2(2.2-6.4)$ \\
White blood cell $\left(\times 10^{3} \mathrm{~mm}^{3}\right)$ & $6.3(6.1-18.8)$ & $6.9(5.4-10.2)$ \\
lgG $(\mathrm{mg} / \mathrm{dl})$ & $847(549-1145)$ & $160(70.5-902.3)$ \\
lgM (mg/dl) & $93.8(36.7-749)$ & $70.2(56.9-86.1)$ \\
C3 $(\mathrm{mg} / \mathrm{dl})$ & $108(54-311)$ & $88(88-158)$ \\
C4 $(\mathrm{mg} / \mathrm{dl})$ & $23(10-75.4)$ & $16.9(10-83)$ \\
\hline
\end{tabular}

* Data presented as median (range) apart from the female:male ratio.

\section{Methods}

\section{Subjects}

The patients with RA were enrolled from the outpatient clinical service of the University HospitalUFSC by reviewing their medical records. Only patients with positive results for RF who fulfilled the American College of Rheumatology diagnostic criteria for $\mathrm{RA}^{10,11}$ were selected for inclusion in the study. Exclusion criteria were the presence of other acute or chronic inflammatory diseases. Apparently healthy persons were asked to participate as controls if they had negative $R F$ values and an absence of acute and chronic diseases. All patients and subjects gave informed consent, and the Medical Ethics Committee of the Universidade Federal of Santa Catarina approved the study protocol.

\section{Procedures}

All laboratory specimens for the study were collected at the time the patients came to the clinical laboratory for other reasons. Blood samples were drawn from the antecubital vein in the fasting state. Some evaluations such as ESR, RF and haematological parameters were made as part of a standard battery of assessments requested by their doctors. Samples were collected in different tubes according to the type of analysis. ESR and haematological parameters (red and white blood cell indices: number, haematocrit, haemoglobin, platelet number) were obtained from the samples using different anticoagulant solutions: sodium citrate and ethylenediaminetetracetic acid, respectively. Silicone-coated tubes were used for other analyses [cytokines, CRP, RF, immunoglobulins $\mathrm{G}$ and $\mathrm{M}$ (IgG and IgM), complement components (C3 and $\mathrm{C} 4), \beta_{2}$-microglobulin and anti-nuclear antibody (ANA) assays]. After being centrifuged, coded serum aliquots were stored at $-20^{\circ} \mathrm{C}$ and analysed for cytokines, CRP, RF, IgG, IgM, C3, C4, $\beta_{2}$-microglobulin and ANA in a single batch at the end of the study. The samples from the control group were submitted to the same procedures.

\section{Measurements}

\section{Serum cytokine assays}

On the day of the measurements of the studied parameters, the samples were thawed to room temperature. Both TNF- $\alpha$ and sIL-2R were measured by enzyme-linked immunosorbent assay (Boehringer Mannheim Biochemical, Indianapolis, Indiana, USA) methodologies. The ranges of the values detected by these assays were: $\mathrm{TNF}_{-} \alpha, 5-1000 \mathrm{pg} / \mathrm{ml}$; and sIL-2R, $50-100 \mathrm{pmol} / \mathrm{l}$. The principle of these tests is based on the two-step sandwich techniques. Briefly, sample aliquots and standards $(20 \mu 1)$ were transferred to the wells of a microtitre plate (TNF- $\alpha, 5-1000 \mathrm{pg} / \mathrm{ml}$; sIL$2 \mathrm{R}, 5-100 \mathrm{pmol} / \mathrm{l})$ and incubated at room temperature $(4 \mathrm{~h})$. Then the samples were washed three times with washing solution (composition: $\mathrm{NaCl}, 137 \mathrm{mM}$; $\mathrm{KCl}$, $2 \mathrm{mM}$; and phosphate, $10 \mathrm{mM}$; $\mathrm{pH} 7.6$ ), followed by the addition of $200 \mu 1$ of substrate solution into the wells. The microtitre plate was then protected from light and maintained at room temperature $(20-30 \mathrm{~min})$. The reaction was stopped by adding $50 \mu 1$ of sulphuric acid $(1 \mathrm{~mol} / \mathrm{l})$. One minute later, the concentration of cytokines in each well was determined (Organon Teknika, Durham, North Carolina, USA). When indicated by the manufacturer, the procedures were carried out on a shaker (250 r.p.m.).

\section{CRP, RF, IgG and IgM, complement components (C3, C4) and ANA assays}

CRP (cut-off, $0.8 \mathrm{mg} / \mathrm{dl}$ ), RF (cut-off, < $20 \mathrm{IU} / \mathrm{ml}$ ), IgG (reference range, 694-1618 mg/dl), IgM (reference range, $60-263 \mathrm{mg} / \mathrm{dl}$ ), C3 (reference range, $88-210 \mathrm{mg} / \mathrm{dl}$ ) and C4 (reference range, $16-47 \mathrm{mg} /$ dl) were measured by nephelometry (Beckman Coulter Array, Brea, California, USA), $\beta_{2}$-microglobulin $(1.01-1.73 \mathrm{mg} / \mathrm{dl})$ was determined by the chemiluminescence method (Immulite 2000; DPC Medlab, Dade, Boehringer, Deerfield, Illinois, USA) and leuko- 
(A)

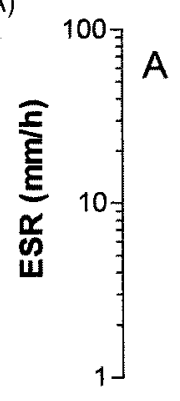

A

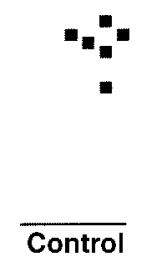

(B)

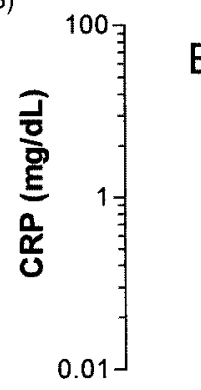

(C)

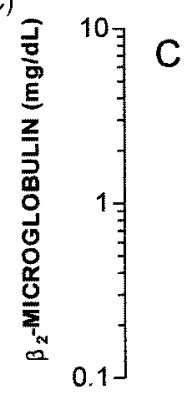

B
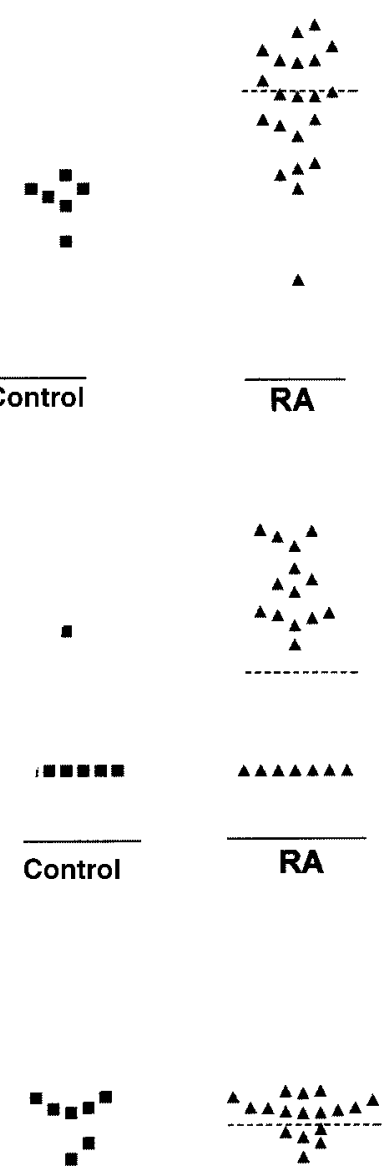

Control

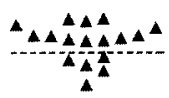

RA

FIG. 1. Individual values of ESR (A), CRP (B) and $\beta_{2}$-microglobulin (C) in both control and RA groups. The dotted line indicates the median.

cyte indexes were determined on an automatic counting machine (Beckman-Coulter). The ESR (cutoff values: female, $<20 \mathrm{~mm} / \mathrm{h}$; male, $<15 \mathrm{~mm} / \mathrm{h}$ ) was measured by the Westergreen method (automatic Vesmastic-20, Miami, Florida, USA). ANA tests were evaluated by indirect immunofluorescence assays using human epithelial cell (HEP-2) slides. ${ }^{10}$

\section{Statistical analysis}

When indicated, the Mann-Whitney test, single linear regression test or correlation (Pearson) analysis were used. For all analyses, $p<0.05$ was used to assess overall differences. The results are expressed as the median and its range.

\section{Results}

The present study included a series of 21 patients; all fulfilled the American College of Rheumatology Diag-
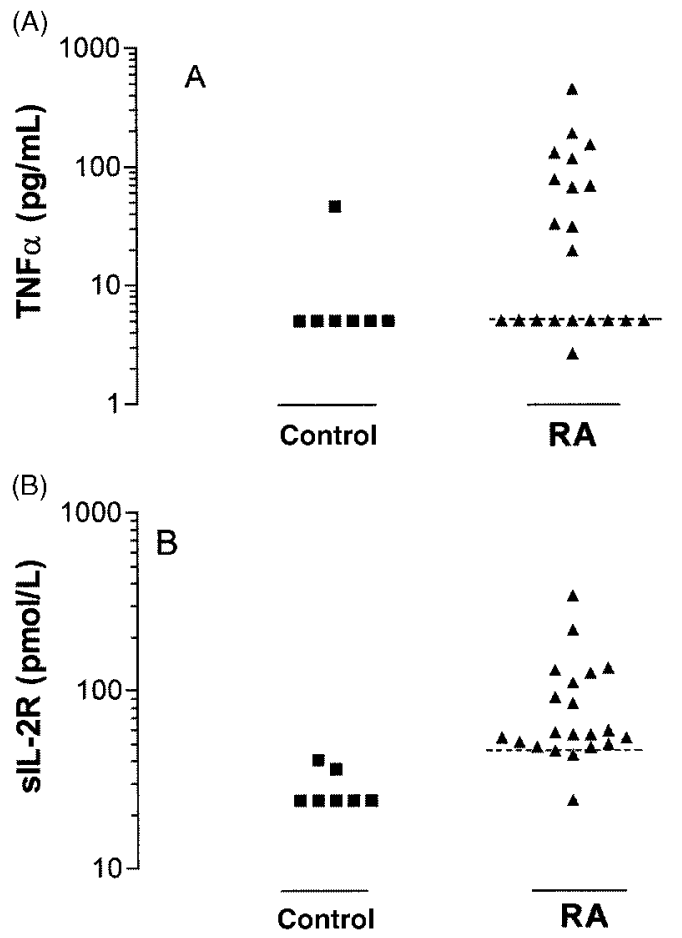

FIG. 2. Individual values of TNF- ${ }_{\alpha}(A)$ and sIL-2R (B) in both control and RA groups. The dotted line indicates the median.

nostic Criteria for $\mathrm{RA},{ }^{10,11}$ and seven apparently healthy individuals were used as controls. The gender ratio was 18 females to three males for RA patients and seven females to zero males for the control group. All patients were white. The median age of the groups was 36 years (range 16-75 years) for the RA group and 29 years (range 20-75 years) for the control group.

Table 1 presents some of the features of the studied groups. As shown, no evidence of anaemia or changes in either platelet or white cell numbers, levels of IgG and IgM or complement factors (C3 and C4) were detected in RA patients (Table 1) $(p>0.05)$. In comparison with the control group, RA patients presented increased levels of ESR, CRP, and $\beta_{2}$-microglobulin $(p<0.01)$ (Fig. 1A-C). The median levels of ESR in RA and groups were $34 \mathrm{~mm} / \mathrm{h}$ (range $3.0-88 \mathrm{~mm} / \mathrm{h}$ ), whereas those for CRP and $\beta_{2}$-microglobulin concentrations were $0.9 \mathrm{mg} / \mathrm{dl}$ (range $0.08-58 \mathrm{mg} / \mathrm{dl}$ ) and $1.6 \mathrm{mg} / \mathrm{dl}$ (range $0.84-2.0 \mathrm{mg} / \mathrm{dl}$ ), respectively. In this studied group of RA patients, only ESR levels significantly differ from control group $(p<$ 0.01). Both $\mathrm{TNF}_{-\alpha}$ (median $6.4 \mathrm{pg} / \mathrm{ml}$, range $2.8-450 \mathrm{pg} / \mathrm{ml}$ ) and sIL-2R (median $56 \mathrm{pmol} / \mathrm{l}$, range 12.5-341 pmol/l) levels were also enhanced in the RA patients (Fig. 2A,B) but they did not differ in comparison with control data.

Table 2 shows that a significant correlation was only found between TNF- $\alpha$ and sIL-2R $(p<0.01)$. However, this statistical significance may be artifactual since no statistical significance was found for the 
Table 2. +Correlation $r$ values among the studied variables $(n=27)$

\begin{tabular}{lcc}
\hline Variables & Linear Regression $r$ & Pearson correlation $r$ \\
\hline ESR versus CRP (log) & 0.53 & 0.53 \\
ESR versus sIL-2R & 0.40 & 0.40 \\
ESR versus RF & 0.10 & 0.10 \\
ESR versus TNF- $\alpha$ & 0.11 & 0.11 \\
ESR versus $\beta 2^{-m i c r o g l o b u l i n}$ & 0.05 & -0.13 \\
RF versus $\beta 2^{-m i c r o g l o b u l i n ~}$ & 0.41 & 0.41 \\
RF versus CRP (log) & 0.19 & 0.19 \\
RF versus slL-2R & 0.16 & 0.16 \\
RF versus TNF- $\alpha$ & 0.18 & 0.17 \\
CRP (log) versus slL-2R & 0.06 & 0.06 \\
CRP (log) versus $\beta 2-$ microglobulin & 0.004 & $-0,064$ \\
CRP (log) versus TNF- $\alpha$ & -0.17 & -0.17 \\
$\beta 2^{-M i c r o g l o b u l i n ~ v e r s u s ~ T N F-~} \alpha$ & 0.25 & 0.25 \\
$\beta 2-$ Microglobulin versus slL-2R & 0.03 & -0.17 \\
TNF- $\alpha$ versus slL-2R & $0.70^{* *} \#$ & $0.70^{* *} \#$ \\
\hline
\end{tabular}

${ }^{*} p<0.01$, log-logarithm values. \# No statistical significance was found, however, when the highest level of both cytokines from one patient of the RA group was removed.

data of a patient that presented the highest levels of both cytokines from the RA group.

\section{Discussion}

The results presented show that the median levels of $\mathrm{TNF}_{-} \alpha$, sIL-2R and CRP, although slightly increased in RA patients, did not differ from a group of apparently healthy subjects. In the RA group, these findings were associated with high levels of ESR, whereas $\beta_{2}$-microglobulin concentrations also did not differ. Overall, these changes are representative of a spectrum of effects that are triggered in response to the autoimmune injury that characterizes RA.

Several clinical and experimental lines of evidence point to TNF- $\alpha$ as an important inflammatory mediator in RA. ${ }^{6,7}$ It is well known that this cytokine is found at high levels in the synovial fluids of RA patients, and that it contributes to both bone and cartilage destruction. ${ }^{12}$ On the other hand, experimental models of arthritis in mice have demonstrated that $\mathrm{TNF}_{-} \alpha$ injection accelerates arthritis, whereas anti-TNF- $\alpha$ injection prevents it. ${ }^{6}$ In our work, we observed that the median blood levels of this cytokine did not significantly differ in comparison with those measured in the control group. Considering that the studied RA patients were also RF-positive, an indicator of disease severity, the relevance of these findings remains to be established. ${ }^{13,14}$

Few studies in the literature have evaluated the levels of sIL-2R in RA patients. Suenaga et al. ${ }^{15}$ have demonstrated that an increased concentration of SIL$2 \mathrm{R}$ in the serum of patients with joint pain is a predictor for the future development of RA. Spadaro et al. ${ }^{16}$ observed that treatment of RA patients with methotrexate for 6 months was able to decrease the levels of both sIL-2R and IL-6. On the other hand, the levels of sIL-2R did not correlate with any future bone or joint changes within 1 year of observation. ${ }^{17}$ In the present study, the serum concentrations of sIL-2R did not significantly differ in comparison with those of controls, whereas ESR levels but not CRP and $\beta_{2}$-microglobulin were significantly increased Altogether, these inflammatory indices seem to independently reflect a final pathway of multifactorial events.

Another point that deserves consideration is the fact that, despite adequate control of symptoms in this disease, the available therapeutic measures do not prevent further progression of this disease that results in high levels of disability. ${ }^{18,19}$ Advances in this field are urged and the provision of adequate therapy is now a common goal for several chronic diseases. In this regard, ultra-sensitive assays of polymerase chain reaction have been used both as markers and prognostic predictors of cardiovascular disease. ${ }^{20,21} \mathrm{How}$ ever, treatment evaluation was not addressed in our work and the small number of RA patients did not permit further conclusions in relation to the polymerase chain reaction levels that were measured by ultrasensitive assay.

In conclusion, the present results show that, in this group of RA patients, all RF negative, the elevated levels of ESR did not correlate with the studied cytokine levels. According to these findings, other inflammatory markers must be searched in order to provide early therapeutic strategies to these group of patients.

ACKNOWLEDGEMENTS. The authors thank José Tadeu Pinheiro, MT and Francine Cargnin, MT for providing excellent technical support during the study, and the Clinical Laboratory of the Hospital Universitário - HU- UFSC and Quimilabor for their kind donation of CRP, RF, IgG, IgM, C3 and C4 kits.

\section{References}

1. Firestein GS. Etiology and pathogenesis of rheumatoid arthritis. In Kelley WN, Ruddy S, Harris Jr, Sledge CB, eds. Textbook of Rbeumatology. Philadelphia, PA: WB Saunders, 1997: 851-897. 
2. Richardson C, Emery P. Laboratory markers of disease activity. $J$ Rbeumatol 1996; 23: 23-30.

3. Tighe H, Carson DA. Rheumatoid factors. In: Kelley WN, Ruddy S, Harris Jr, Sledge CB, eds. Textbook of Rheumatology. Philadelphia, PA: WB Saunders, 1997: 241-249.

4. Pincus T. Rheumatoid arthritis: a medical emergency? Scand J Rheumatol 1994; 100: 21-30.

5. Symmons DPM, Hassell AB, Gunatillaka KAN, Jones PJ, Schollum J, Dawes PT. Development and preliminary assessment of a simple measure of overall status in theumatoid arthritis (OSRA) for routine clinical use. $Q J$ Med 1995; 88: 429-437.

6. Koch AE, Kunkel SL, Striter RM. Cytokines in rheumatoid arthritis. $J$ Invest Med 1995; 43: 28-38.

7. Carteron NL. Cytokines in rheumatoid arthritis: trials and tribulations. Mol Med Today 2000; 6: 315-323.

8. Thornton S, Boivi GP, Kim KN, Finkelman FD, Hirsch R. Heterogeneous effects of IL-2 on collagen-induced arthritis. I Immunol 2000; 65: 557-563.

9. Corrigan VM, Arastu M, Khan S, et al. Functional IL-2 receptor beta (CD122) and gamma (CD132) chains are expressed by fibroblast-like synoviocytes: activation by IL-2 stimulates monocyte chemoattractant protein-1 production. J Immunol 2001; 166: 4141-4147.

10. American College of Rheumatology Ad Hoc Committee on Clinical Guidelines. Guidelines for monitoring drug therapy in rheumatoid arthritis. Arthritis Rheum 1996; 39: 723-731.

11. American College of Rheumatology Subcommittee. Recommendations for the medical management of osteoarthritis of the hip and knee: 2000 update. American College of Rheumatology Subcommittee on Osteoarthritis Guidelines. Arthritis Rheum 2000; 43: 1905-1915.

12. Maini RN. The role of cytokines in rheumatoid arthritis. The Croonian lecture. J R Coll Phys Lond 1995; 30: 344-351.

13. McDermot MF.TNF andTNFR biology in health and disease. Cell Mol Biol 2001; 47: 619-635.
14. Mugnier B, Bouvenot $G$. Les anticorps monoclonaux anti-TNF $\alpha$ dans traitement de la polyarthrite rhumatöde. Rev Méd Interne 2000; 21 $854-862$.

15. Suenaga $Y$, Yasuda $M$, Yamamoto $M$, Nonaka $S$, Wada $T$, Shiokawa $S$, Nobunaga M. Serum interleukin receptor for the early diagnosis of rheumatoid arthritis. Clin Rbeumatol 1998; 17: 311-317.

16. Spadaro A, Taccari E, Riccieri V, Sensi F, Sili Scavalli A, Zoppini A Relationship of soluble interleukin-2-receptor and interleukin-6 with class-specific rheumatoid factors during low-dose methotrexate treatment in rheumatoid arthritis. Rev Rheum Engl 1997; 64: 89-94.

17. Merkel PA, Dooley MA, Dawson DV, Pisetsky DS, Polisson RP. Interleukin2 receptor levels in sera of patients with rheumatoid arthritis treated with sulfasalazine, parenteral gold, or placebo. J Rbeumatol 1996; 23 856-861.

18. Butler DM, Maini RN, Feldmann M, Brennan FM. Modulation of proin flammatory cytokine release in rheumatoid synovial membrane cell cultures. Comparison of monoclonal anti-TNF $\alpha$ antibody with the interleukin-1 receptor antagonist. Eur Cytokine Network 1995; 6: 225-230.

19. Moller HJ. Connective tissue markers of rheumatoid arthritis. Scand J Lab Invest 1998; 58: 269-278.

20. Rifai N, Ridker P. High-sensitivity C-reactive protein: a novel and promising marker of coronary heart disease. Clin Chem 2001; 47 403-411.

21. Koening W. C-reactive protein and cardiovascular risk: has the time come for screening the general population? Clin Chem 2001; 47: 9-10.

\section{Received 6 August 2002 \\ Accepted 1 October 2002}




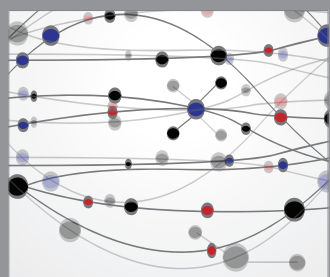

The Scientific World Journal
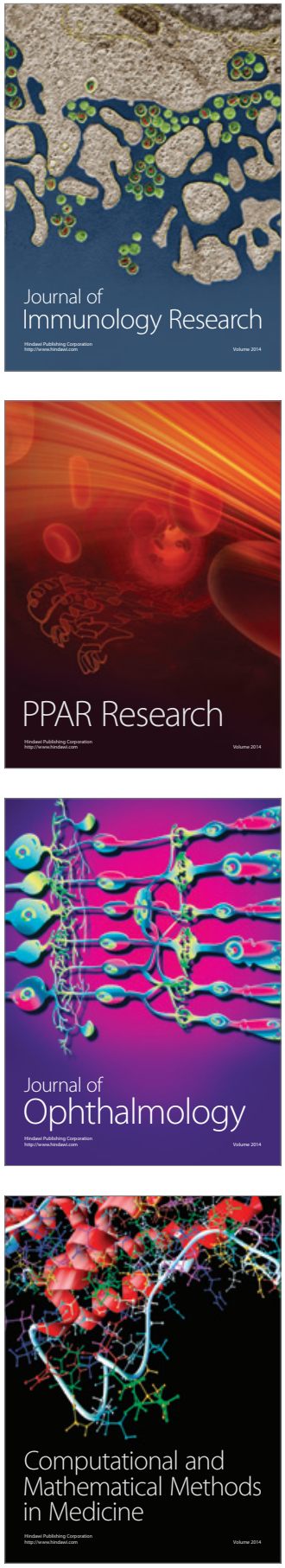

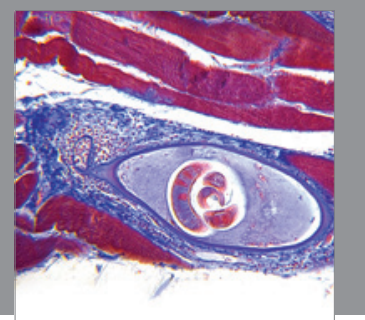

Gastroenterology

Research and Practice
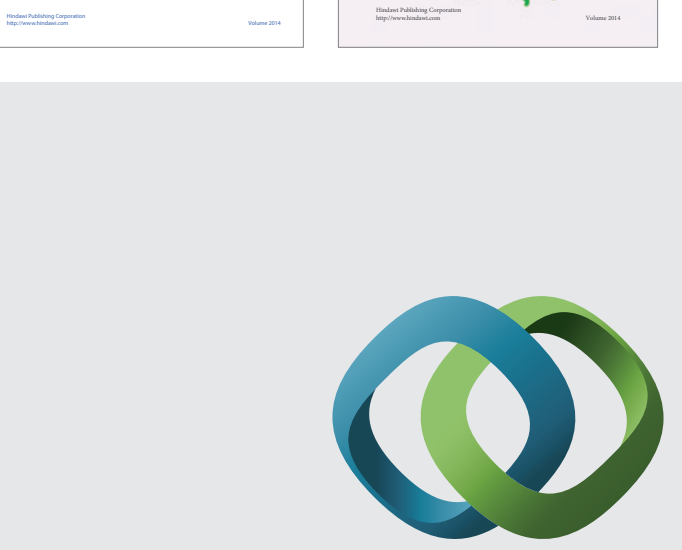

\section{Hindawi}

Submit your manuscripts at

http://www.hindawi.com
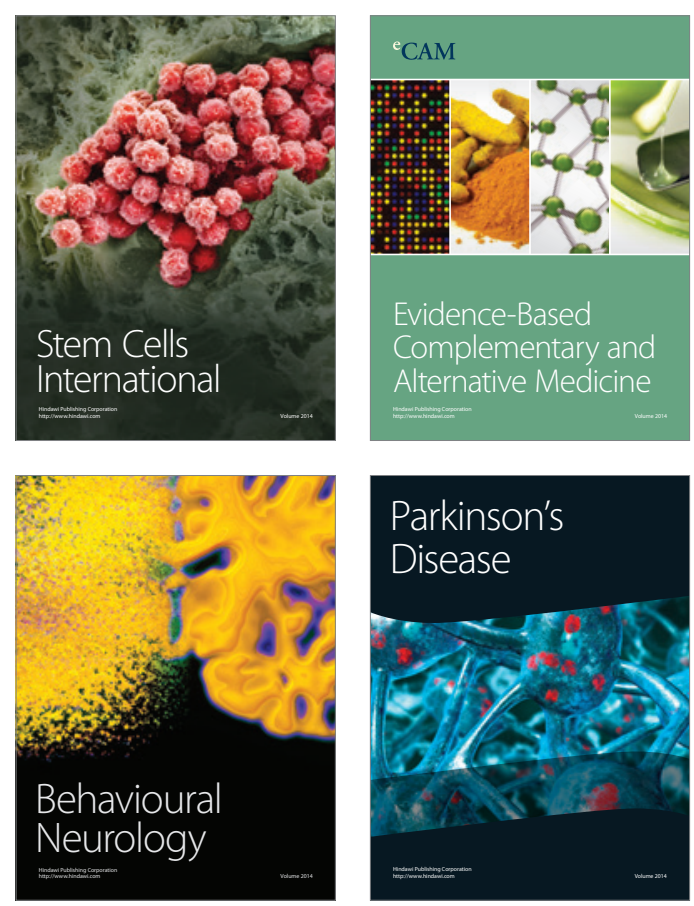

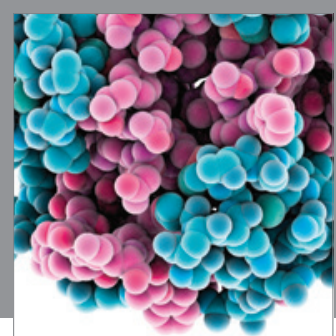

Journal of
Diabetes Research

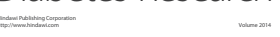

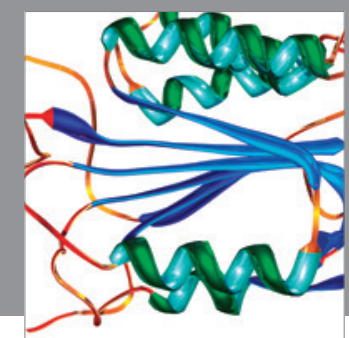

Disease Markers
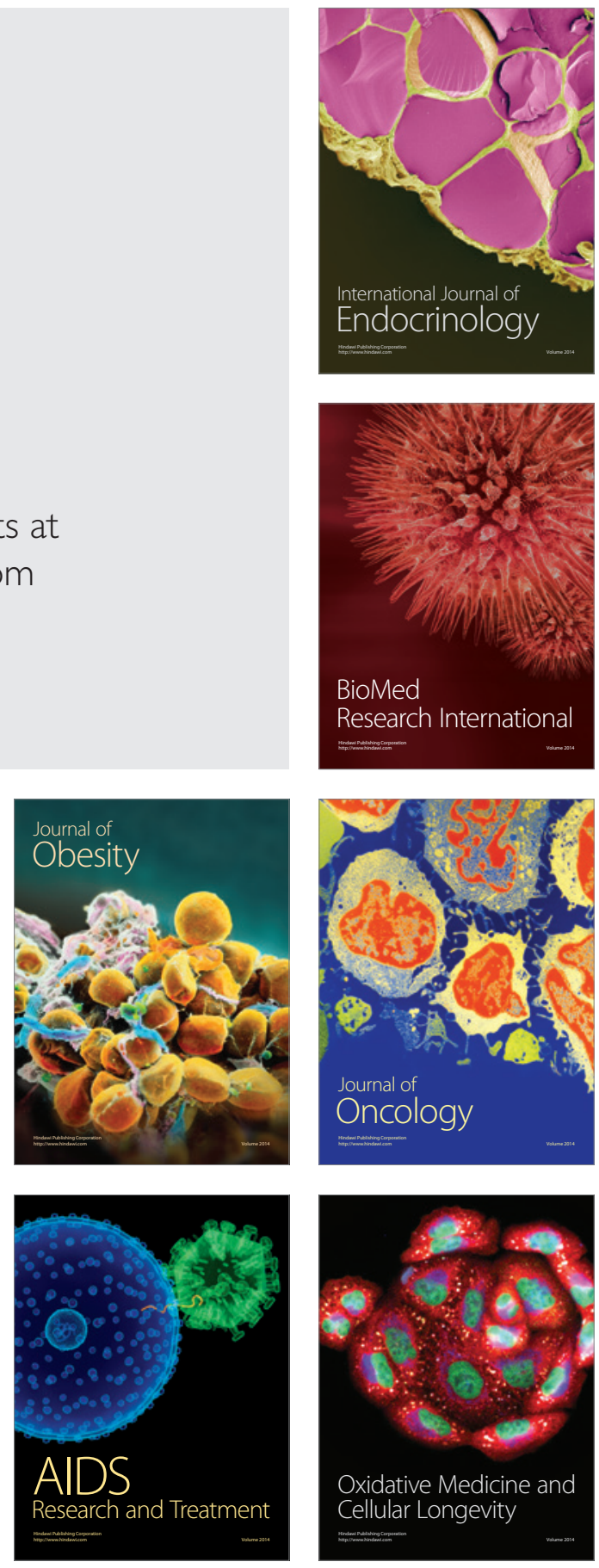